\title{
gêneros, sexualidades e infâncias: cenas de crianças na contramão da inocência
}

\author{
raquel gonçalves salgado ${ }^{1}$ \\ universidade federal de mato grosso - brasil \\ leonardo lemos de souza ${ }^{2}$ \\ universidade estadual paulista júlio de mesquita filho - brasil
}

resumo

A aura sagrada e secular da inocência em torno da infância mantém ainda, nos dias de hoje, sua força nos discursos sociais de proteção, cuidado e educação das crianças. Conjugado a essa aura de inocência está o discurso do desenvolvimento infantil, muito caro à psicologia e à educação, que se esforça em descrever e caracterizar minuciosamente a infância como uma "etapa da vida", como forma de afirmar "verdades" sobre os sujeitos que a vivem e como "devem" vivê-la. Desse modo, nosso propósito, com este trabalho, é problematizar a produção discursiva da criança inocente, no campo da psicologia e da educação, pelo viés da crítica feminista e dos estudos da infância. Para tanto, assumimos como principais interrogantes o gênero e a sexualidade como possibilidades de construir outros olhares sobre a infância ao nos debruçarmos sobre as experiências, os conhecimentos e os sentidos que as crianças compartilham em suas produções culturais lúdicas. As cenas que trazemos à baila como suportes de nossas reflexões advêm de pesquisas com crianças em instituições de Educação Infantil, da rede pública municipal de ensino de Rondonópolis, Mato Grosso, Brasil, desenvolvidas no âmbito do grupo de pesquisa "Infância, Juventude e Cultura Contemporânea" (GEIJC). As principais questões que levantamos com os marcadores de gênero e sexualidade, quando os levamos para o contexto escolar, são: (1) o lugar das crianças no direito de expressarem seus gêneros e sexualidades nesse contexto; (2) a possibilidade de essas expressões serem reconhecidas e terem existências despatologizadas e viáveis em contextos de aprendizagem, bem como a sua desvinculação de valores moralistas e excludentes; e (3) a possibilidade de reconhecimento, pela escola e pelas políticas cognitivas gestadas nesse contexto, de trajetórias distintas das expressões de gênero e sexuais de crianças. Em suma, nossas indagações vão no sentido de problematizar a ideia de desenvolvimento como progresso a um "dever ser" orientado pela linearidade e universalidade das expressões de gêneros e sexuais, que desemboca com força nos discursos pedagógicos por uma identidade falocêntrica, masculinista, heteronormativa, binária e burguesa.

palavras chave: infâncias; gêneros; sexualidades; feminismos; educação.

\section{gender, sexuality and childhood: children scenes against innocence}

abstract

The sacred and secular aura of innocence around childhood is still nowadays well preserved, having a strong impact on social discourses of protection; care and education. Conjugated to this aura is the child developmental discourse; very crucial to psychology and education; which strives to thoroughly describe and characterise childhood as a "life stage"; in order to claim "truths" about subjects who live it and how they "must" live it. In this way; our proposal with this work is to question the discursive production of "innocent child"; in psychology and education fields; through a feminist perspective and the childhood studies. Therefore; we assume as principal question figures gender and

\footnotetext{
${ }^{1}$ E-mail: danjubinha@gmail.com

2 E-mail: leo.lemos.souza@gmail.com
} 
sexuality as possibilities to construct different views on childhood by looking over the experiences; the knowledge and senses that children are sharing in their playing cultures. The scenes we bring up as supports to our reflections come from researches with children in pre-school municipal public institutions; in Rondonópolis; Mato Grosso; Brazil; conducted in the scope of Childhood; Youth and Contemporary Culture Research Group (GEIJC). The main questions we raise with gender and sexuality as markers; when we take them to the scholar context; are: (1) the children's place in their right of expressing their genders and sexualities in this context; (2) the possibility of these expressions to be recognized and have despatologised and viable existences in learning contexts; as well as their detachment from moral and excluding values; and (3) the possibility of recognition; by the school and cognitive politics produced in this context; of different trajectories of gender and sexual expressions in children. In summary; our inquiries are directed to question the developmental idea as a progress to a "must be" oriented by linearity and universality of gender and sexual expressions; which debouch intensely in pedagogical discourses in search of a phallocentric; masculinist; heteronormative; binary and bourgeois identity.

keywords: childhoods; genders; sexualities; feminisms; education.

\section{géneros, sexualidades e infancias: escenas de niños en la contramano de la inocencia}

resumen

El aura sagrada y secular de la inocencia en torno a la infancia mantiene aún, hoy en día, su fuerza en los discursos sociales de protección, cuidado y educación de los niños. Conjugado con ese aura de inocencia está el discurso del desarrollo infantil, caro para la psicología y para la educación, que se esfuerza en describir y caracterizar minuciosamente la infancia como una "etapa de la vida", como forma de afirmar "verdades" sobre los sujetos que la viven y sobre cómo "deben" vivirla. Nuestro propósito con este trabajo es problematizar la producción discursiva sobre el niño inocente en el campo de la psicología y la educación siguiendo el camino de la crítica feminista y de los estudios de la niñez. Para ello, asumimos como principales interrogantes el género y la sexualidad como posibilidades de construir otras miradas sobre la infancia al contemplar las experiencias, los conocimientos y los sentidos que los niños comparten en sus producciones culturales lúdicas. Las escenas que traemos para este propósito como soportes de nuestras reflexiones provienen de investigaciones con niños en instituciones de Educación Infantil de la red pública municipal de enseñanza de Rondonópolis (Mato Grosso, Brasil). El trabajo fue desarrollado en el ámbito del grupo de investigación "Infancia; Juventud y Cultura Contemporánea" (GEIJC). Las principales cuestiones que planteamos como marcadores de género y sexualidad cuando los llevamos al contexto escolar fueron: (1) el lugar de los niños al derecho a expresar sus géneros y sexualidades en ese contexto; (2) la posibilidad de que dichas expresiones sean reconocidas y tengan existencias despatologizadas y viables en contextos de aprendizaje, así como su desvinculación de valores moralistas y excluyentes; y (3) la posibilidad de reconocimiento, por parte de la escuela y de las políticas cognitivas gestadas en ese contexto, de trayectorias distintas de las expresiones de género y sexuales de niños. En suma, nuestras indagaciones van en el sentido de problematizar la idea de desarrollo como progreso a un "deber ser" orientado por la linealidad y universalidad de las expresiones de géneros y sexualidades, que desemboca con fuerza en los discursos pedagógicos por una identidad falocéntrica, masculinista, heteronormativa, binaria y burguesa.

palabras clave: infancias; géneros; sexualidad; feminismos; educación. 
gêneros, sexualidades e infâncias: cenas de crianças na contramão da inocência

\section{introdução}

A família nuclear e a escola consolidam-se, historicamente, como instituições que, por meio de suas práticas e códigos sociais, fundam um campo discursivo da infância que vai ganhando força e materialidade na vida social. Nessa rede discursiva, a inocência consagra-se como o atributo emblemático da infância, que, com um sentido mítico, acaba por se estabelecer como uma espécie de "natureza infantil". Decorrem desse binômio infância-inocência representações que ancoram valores, práticas sociais e políticas, que circunscrevem as relações entre crianças e adultos. Conjugado a esse binômio, também, está o discurso do desenvolvimento infantil, muito caro à psicologia e à educação, que se esforça em descrever e caracterizar minuciosamente a infância como uma "etapa da vida", como forma de afirmar "verdades" sobre os sujeitos que a vivem e como "devem" vivê-la.

Problematizar esse discurso da criança-inocente como um dos pontos de sustentação da matriz ontológica da infância, produzida pelo sistema de pensamento moderno e ocidental, assumindo o gênero e a sexualidade como interrogantes, é o principal viés deste trabalho. Neste sentido, as questões que aqui levantamos partem de outras possibilidades de compreender situações vividas no contexto de uma das pesquisas desenvolvidas, no âmbito do Grupo de Pesquisa "Infância, Juventude e Cultura Contemporânea" (GEIJC), pertencente ao Programa de Pós-graduação em Educação (PPGEdu), da Universidade Federal de Mato Grosso (UFMT), do Câmpus de Rondonópolis, Mato Grosso, Brasil. Trata-se de uma pesquisa realizada com crianças de uma turma da Educação Infantil, entre cinco e seis anos de idade, de uma Unidade Municipal de Educação Infantil (UMEI), da rede pública de ensino do município de Rondonópolis, que teve como foco principal analisar as experiências lúdicas das crianças, como forma de compreender os sentidos que elas constroem nas relações e nos grupos que 
gêneros, sexualidades e infâncias: cenas de crianças na contramão da inocência

compõem para brincar ${ }^{3}$. Nessa investigação, os encontros com as crianças ocorreram semanalmente no decorrer do ano letivo de 2005 e tiveram como viés metodológico a pesquisa intervenção, em que as relações estabelecidas entre participantes (crianças e professoras da turma ${ }^{4}$ ) e pesquisadores se definem, ao mesmo tempo, como objeto de investigação e reflexão. Nessa dupla dimensão da pesquisa, tanto as crianças quanto as professoras não são apenas informantes de dados a serem traduzidos pelo texto analítico dos pesquisadores, de modo que a investigação se constitui nas relações estabelecidas, numa via de mão dupla, entre as pessoas envolvidas no processo de pesquisa. A observação participante das experiências lúdicas das crianças e os registros em diário de campo consistiram nas principais estratégias metodológicas durante a pesquisa.

Os excertos dos diálogos com as crianças que aqui trazemos têm como tônica os modos como a sexualidade aparece como discurso recorrente em um grupo de meninas da turma, assunto este que, mesmo compartilhado em um contexto lúdico, gerou muitas controvérsias, dado o caráter profano que assume quando em choque com a imagem da criança inocente. Tais excertos já foram analisados e discutidos em outros artigos ${ }^{5}$, mas sob outros vieses e partindo de outras questões. Nosso propósito aqui, portanto, é retomar o debate sobre essas experiências lúdicas das meninas a partir de uma perspectiva feminista e dos estudos da infância, que assumem o gênero e a sexualidade como interrogantes que permitem construir outros olhares sobre a infância, ao nos debruçarmos sobre as experiências, os conhecimentos e os sentidos que as crianças compartilham em

\footnotetext{
${ }^{3} \mathrm{O}$ projeto de pesquisa intitulou-se "Infância e cultura lúdica contemporânea: a criança entre brinquedos, narrativas, saberes e competências", esteve sob a coordenação da Profa. Raquel Gonçalves Salgado, e contou com a participação de Cíntia de Sousa Carvalho, Daniela Patrícia de Oliveira, George Moraes de Luiz e Maria Auxiliadora Campos Rodrigues, que, na ocasião, atuaram como estudantes de Iniciação Científica.

${ }^{4}$ Além das crianças, contamos, nessa pesquisa, com a participação de duas professoras - uma que atuava no período matutino e outra no vespertino.

5 SALGADO, Raquel Gonçalves; CARVALHO, Cíntia de Sousa; RODRIGUES, Maria Auxiliadora Campos. Quando as meninas brincam de ser mulher: reflexões sobre mídia, cultura lúdica, gênero e sexualidade. In: PASSOS, Mailsa Carla Pinto; PEREIRA, Rita Marisa Ribes. (org.). Identidade, diversidade: práticas culturais em pesquisa. Rio de Janeiro: DP et alii; FAPERJ, 2009, p. 43-54 e CARVALHO, Cíntia de Sousa; SILVA, Elisângela Ribeiro da; JOBIM E SOUZA, Solange; SALGADO, Raquel Gonçalves. Direitos sexuais de crianças e adolescentes: avanços e entraves. Psicologia Clínica, vol. 24, n. 1, 2012, p. 69-88.
} 
suas produções culturais lúdicas, para além das redomas e das vigilâncias do olhar adulto enclausurado nos ideais da inocência e do desenvolvimento.

\section{a infância nas redomas da inocência: gênero e sexualidade como interrogantes}

É no século XVII que, na cultura ocidental, a noção de inocência infantil se impõe, com o enaltecimento da fragilidade e vulnerabilidade das crianças. Elas as crianças -, ao serem comparadas com os anjos, ficam envoltas no manto sagrado da inocência como marca de sua impecabilidade. Até o início desse século, como nos mostra Foucault (2006, p. 09), os "corpos pavoneavam" sem incômodo nem descanso. Já no auge desse mesmo século, a sexualidade também é expurgada da vida coletiva e cuidadosamente encerrada no quarto do casal. A ordem familiar moderna encerra-a na função de reproduzir e atribui ao casal a legitimidade de dizer sobre ela e normatizá-la, nomeando-a como segredo.

Mais do que repressão, destaca Foucault (2006), o que o século XVII inaugura é um sistema poder-saber-prazer, no qual a sexualidade se apresenta como dispositivo privilegiado. A sociedade vitoriana burguesa, no auge do capitalismo, ao pensar, regrar e valorar a sexualidade, a coloca no campo do discurso ao mesmo tempo em que a enclausura na ordem do segredo. Ao tornar-se fato discursivo, a sexualidade passa a funcionar como um dispositivo de poder que se prolifera pelos mais diversos canais: instituições sociais, espaços, regulamentos e condutas. No caso das crianças, as escolas são fortes espaços sociais em que a sexualidade escoa como discurso, que quanto mais se enuncia, mais adquire existência como algo a ser contido e disciplinado; mais ganha efeitos de poder. O espaço da sala de aula, dos pátios, dos refeitórios, dos dormitórios, o arranjo das mesas e cadeiras, tudo isso fala de maneira prolixa da sexualidade das crianças como forma de constatar e controlar sua existência (FOUCAULT, 2006).

Na lógica desse sistema poder-saber-prazer, a sexualidade das crianças não se apresenta como um inimigo a ser combatido e derrotado, mas como um ponto de apoio, de modo que a sua perseguição, fiscalização e vigilância só ganham eficácia e funcionalidade mediante a sua incitação. O poder avança e intensifica as suas proporções à medida que o seu alvo se difunde e ramifica, compondo o que 
Foucault denomina como "linhas de penetração infinitas" (FOUCAULT, 2006, p. 50). Não se desenham fronteiras para os prazeres e as sexualidades, ao contrário, suas diversas formas de manifestação são convocadas pelo poder com o propósito de demarcá-las nos corpos e instaurar modos de categorização das pessoas, que são postos em prática por dispositivos e estratégias discursivas presentes nas instituições psiquiátricas, nas escolas e nas famílias. Em se tratando das crianças, chama-nos a atenção o funcionamento aparentemente ambíguo desses dispositivos e como se aliam à produção de saberes, o que fica evidente na afirmação de Foucault de que o "exame médico, a investigação psiquiátrica, o relatório pedagógico e os controles familiares funcionam como mecanismos de dupla incitação: prazer e poder" (FOUCAULT, 2006, p. 52).

Corpos infantis plurais, diversos, contraditórios e híbridos não podem sobreviver porque, na lógica desenvolvimentista, a criança representa a "inocência original" que marca o começo de toda história narrada por uma política reprodutiva (HARAWAY, 2016, p. 89). Não se reconhece o direito da criança a esse corpo assumido como origem: seus corpos são sempre ditos, cuidados, protegidos, definidos e governados pelos adultos, pois, como afirma Preciado (2013, p. 98), "a criança é um artefato biopolítico que garante a normalização do adulto."

A infância, ao ser enunciada no conjunto de estratégias da sexopolítica, se naturaliza, mecanismo pelo qual é erigida a demarcação entre normalidade e anormalidade. Disso decorre a necessidade de manutenção dessas estratégias e mecanismos, bem como dos regimes discursivos que os sustentam, a qual é atendida mediante a coerência e a unidade da experiência infantil em relação a uma identidade de gênero normativa (FERREIRA, 2016).

A ideia de uma identidade de gênero, marcada pela coerência e unicidade, sustentada no binarismo, que é o alinhamento entre sexo e gênero, e definida por sua subordinação ao "corpo sexuado" pela natureza, como Butler (2016) argumenta, é também cúmplice da sexopolítica promovida pela lógica desenvolvimentista. Nessa lógica, meninos e homens definem-se por seus corpos masculinos, bem como meninas e mulheres, por seus corpos femininos. Entretanto, para Butler, gênero é um feito e, por isso, tem seus efeitos. Um destes é 
a "estilização" (BUTLER, 2016, p. 242) do corpo, que abarca os gestos, movimentos e estilos corporais habituais na composição de um "eu" marcado pelo gênero. É nesta perspectiva que não há um gênero substantivo, afirma Butler, mas sim performativo, uma vez que até mesmo a sua univocidade decorre de discursos assentados na coerência sexo-gênero, que vão regular a estrutura binária.

As aprendizagens dessas estilizações corporais, que marcam os gêneros, fazem parte do cotidiano dos processos educativos, desde a mais tenra idade, na vida das crianças pequenas, posto que é nas relações sociais, tanto com educadores quanto com colegas, que o corpo da criança ganha relevo, sendo alvo de processos de feminilização e masculinização (BUSS-SIMÃO et al, 2010; VIANNA; FINCO, 2009). Nesse contexto, gestos, movimentos, posturas e olhares assumem alinhavos sociais. Como Vianna e Finco (2009) destacam, as relações das crianças na Educação Infantil consistem em um dos modos privilegiados de introduzir meninos e meninas na vida social. Seus corpos não são apenas cuidados, mas principalmente educados, uma vez que se configuram como instâncias significadas e marcadas pelos adultos, constituindo o que Buss-Simão et al (2010) apontam como uma educação corporal.

Retomando os discursos e as práticas que constituem a sexopolítica e sua requisição para que meninos e meninas se conformem a identidades de gênero e sexuais coerentes (FERREIRA, 2016), novamente, nos deparamos com a necessidade de uma infância enclausurada, seja nos ditames do desenvolvimento seja na moralidade da inocência.

\section{a infância na contramão da retórica do desenvolvimento humano: quando as meninas brincam de "prexecar"}

A ideia do desenvolvimento humano é partícipe direta do projeto social da modernidade e adere com perfeição à perspectiva de progresso, que tanto se faz útil à vida produtiva de uma nação quanto à trajetória de vida de uma pessoa singular. Sob a cortina do progresso, dominações e explorações de toda ordem são convocadas, sejam coloniais, patriarcais ou ecológicas, e, nesse afã desenvolvimentista, diversas opressões e desigualdades são praticadas, reiteradas 
e legitimadas: “A ideia de estágios de desenvolvimento reflete e reorganiza grandes eixos de desigualdade dentro e entre as sociedades - então organizadas em torno de gênero, 'raça' e relações de classe, orientação sexual e (in)capacidade, bem como idade." (BURMAN, 2009, p. 270; grifo da autora).

A psicologia do desenvolvimento, mais do que uma teoria científica, funciona como uma importante instituição social que produz representações da infância na modernidade, determinando o que é normal e patológico, o que é desejável e o que não o é (BROUGHTON, 1987; CASTRO, 1999). Desse modo, desenvolver-se significa ter que percorrer uma linha reta, cujo início marca o germe do autocontrole e da adaptação social, metas que deverão ser alcançadas gradativamente no decorrer da vida. O desenvolvimento, nesta perspectiva, requer uma finalidade, um telos, marcado pela maturidade, definida em termos biológicos, cognitivos e de socialização. A infância, nessa linha do tempo cronológico, representa o estado lacunar e inacabado do desenvolvimento, que deve caminhar progressivamente em direção ao estágio mais avançado, representado pela vida adulta. Nessa lógica, o objetivo da transformação individual ganha destaque. Tornar-se uma pessoa melhor, modificar-se por estar em crescimento e em desenvolvimento demonstra a determinação da otimização pessoal, metas estas que estão em estreita consonância com os ideais e as políticas do capitalismo neoliberal e penetram nas vidas das crianças e nos currículos da educação básica (BURMAN, 2011).

Esses aparatos discursivos do desenvolvimento humano criam o que Palmary e Mahati (2015 apud BURMAN, 2015) denominam de criança imaginária que se desprende das crianças da vida social, mas que, ao mesmo tempo, se configura como o espelho no qual todas as crianças devem se mirar.

Adquirir o comando do ser, possuir e manter uma identidade centrada são requisitos para a estruturação de uma identidade ocidental que muito se assemelhada à identidade de gênero. Como declara Haraway (2004, p. 220): “Não ter a propriedade do eu é não ser sujeito e, portanto, não ter capacidade de atuação." Eis o que se espera e o que se vislumbra no horizonte do desenvolvimento humano sob a perspectiva do progresso. 
Tecer uma compreensão sobre as experiências lúdicas das crianças que não esteja encerrada nos enquadres discursivos da infância atrelada à inocência e ao desenvolvimento é um dos propósitos deste trabalho. Para tanto, resgatamos aqui as situações lúdicas vividas por um grupo de meninas da turma de Educação Infantil, com a qual trabalhamos em uma de nossas pesquisas, em que assuntos relativos à sexualidade tiveram destaque.

A perspectiva dos direitos sexuais de crianças e adolescentes foi a que conduziu as análises que fizemos na ocasião da publicação do artigo de Carvalho et al (2012), no qual indaga-se a prevalência, na agenda do debate sobre esse tema, do combate ao abuso, exploração e violências sexuais, ou seja, a tônica centra-se em torno dos aspectos negativos e dos riscos ao sufocar outras possibilidades de reflexão e análise que possam redimensionar o assunto para uma compreensão dos sentidos e das experiências que crianças e adolescentes estão construindo em suas relações subjetivas. Esse outro viés, de modo algum, desqualifica a importância do debate sobre as violências sexuais e de gênero que se fazem presentes nas vidas de crianças e adolescentes, mas abre brechas para a escuta dessas pessoas, no sentido de conhecer o que sentem, pensam e vivem, sem a imposição de uma agenda moral que muito mais vigia, fiscaliza e julga do que dialoga e compreende o outro nas suas diferenças.

Reproduzimos aqui o excerto da pesquisa, já analisado e discutido por Carvalho et al (2012), como forma de lançar outras questões sobre o que as crianças compartilham e os discursos que ancoram os modos de operar da instituição educativa em que tais experiências acontecem.

\footnotetext{
Três meninas manipulam bonecas da Barbie, cochicham, riem e olham para os lados, na tentativa de garantir que nenhum adulto, que não os pesquisadores, se aproxime:

Bruna6: Eu vi uma mulher sentada em cima de uma mulher e eu vi a mulher em cima da cadeira namorando com uma mulher.

Pesquisadora: Você viu uma mulher namorando uma mulher, na cadeira? Como você viu? Onde você viu, Bruna?

Bruna: Na televisão.

Pesquisadora: Na televisão? Lá na sua casa? Que horas você viu na televisão?

Bruna: Ela prexecou.

$[\ldots]$
}

\footnotetext{
${ }^{6}$ São utilizados nomes fictícios como forma de preservar as identidades das crianças.
} 
Ana: A minha mãe também deixou eu ver. Eu vi a mulher "prexecando" em cima da mulher.

Pesquisadora: É?

Ana: O homem tirou o pinto, e a mulher tirou a "prexeca" e colocou no homem ${ }^{7}$.

Joana: Nós vimos pelado (Diário de campo). (CARVALHO et al, 2012, p. 76)

As cenas trazidas pelas crianças nesse diálogo remetem às brincadeiras de "prexecar" compartilhadas por algumas meninas da turma, que, ao falarem de "sexo", acabam por terem em mãos um passaporte importante que as permite atravessar a fronteira erigida entre infância e vida adulta, o que, de certo modo, as confere um protagonismo no grupo de crianças (SALGADO et al, 2009). No entanto, essas brincadeiras não aconteciam em público, na presença das professoras, mas nos espaços escondidos e reservados da sala de aula, como os cantos e debaixo de uma das mesas.

Ao verem as meninas brincando debaixo da mesa com bonecas Barbies e o boneco $\mathrm{Ken}^{8}$, as pesquisadoras se aproximam e iniciam com elas um diálogo sobre o que veem.

Bruna: Ela beijou na prexeca dela. E ele gostou. Olha a cara dele, olha aqui!

Pesquisadora: Cara de feliz, Bruna! E onde é a prexeca dela? Mostra aí na boneca.

Bibi: Aqui. (Ela aponta para a região dos órgãos genitais).

Pesquisadora: Por que ele beijou aí? O que eles estão fazendo?

Bruma: É porque eles tava namorando, ele beijou aqui e ela gostou.

Pesquisadora: E ela achou bom também? (Perplexa com a resposta de Bruna).

Bruna: E ela sorria. Oh, você quer ver oh! Deixa eu tirar a roupa dele.

Pesquisadora: Mas o que é que eles são? Eles podem fazer isso?

Júlia: São namoradinho.

Pesquisadora: São namoradinho? E namoradinho pode beijar na prexeca da outra? (Afirmam com a cabeça).

São muitas as dúvidas que pairam, diante dos excertos acima, causando assombros e pânicos, principalmente quando levantadas sob a égide de uma sexopolítica da infância (FERREIRA, 2016): meninas que assistem a filmes pornográficos na TV? Meninas que presenciam cenas de relações homoafetivas?

\footnotetext{
${ }^{7}$ Nos relatos dessas crianças, "prexecar" designava a relação sexual em que as mulheres "engoliam os homens", sugerindo certo protagonismo feminino no ato sexual.

${ }^{8}$ Boneco confeccionado para ser o parceiro da boneca Barbie.
} 
Como pode a mãe autorizar o acesso de uma criança a cenas de conteúdo sexual explícito e que remetem à homossexualidade? Como pode crianças (meninas) tão pequenas estarem falando desses assuntos e ainda trazerem-nos para os enredos de suas brincadeiras com as bonecas e os bonecos? São perguntas que se sustentam em fortes apelos morais e não esperam respostas porque não advêm de uma busca por compreensão, mas sim da necessidade de julgar, advertir, controlar e gerir os corpos, as fantasias e as experiências das crianças.

Em nome da inocência e do desenvolvimento normativos, cada manifestação das crianças que vai na contracorrente da infância ideal precisa ser capturada pelos aparatos institucionais que as conformam a um "dever ser". Não é de se espantar o fato de a coordenação da instituição educativa, ao tomar ciência das brincadeiras "profanas" das meninas, decidir retirar da sala de aula a mesa e o único boneco Ken que havia nesse espaço. Essa iniciativa foi adotada como forma de promover outros modos de brincar (os "autorizados"), cujos enredos envolvessem temas próprios e adequados ao que se espera de uma criança e, neste caso especialmente, ao que é demandado a uma menina (CARVALHO et al, 2012). Muito mais do que repressão, a retirada dos objetos lúdicos da sala de aula remete à necessidade de gerir a infância, com o efeito de disciplinar a sexualidade das crianças a cada instante em que esta se mostra e se enuncia (FOUCAULT, 2006). O espaço da sala de aula precisa ser organizado e planejado para pôr em funcionamento essa gestão.

Apesar dos esforços institucionais para impedir as brincadeiras transgressoras das meninas, elas não se rendem e o "prexecar" continua sendo tema privilegiado das brincadeiras de namoro entre as bonecas Barbie, que acontecem agora sem o Ken e nos cantos da sala de aula (CARVALHO et al, 2012).

Os apelos morais que ganham corpo nas práticas institucionais de vigilância e controle declaram o modo literal como as brincadeiras das crianças são comumente interpretadas pelos adultos que as educam. Se até mesmo os enunciados nos diálogos da comunicação ordinária constituem-se no embate de vozes sociais, dada a intensa disputa de sentidos que os inserem no fluxo ininterrupto da vida social e da história (BAKHTIN, 1992), o que não dizer 
daqueles imersos nos diálogos lúdicos das crianças? Interpretar os enunciados das crianças em uma situação lúdica como palavras dicionarizadas, que remetem a um significado unívoco, implica em uma compreensão restrita da dialogia que elas produzem ao imprimir o tom da literalidade a uma linguagem que é múltipla e plural.

$\mathrm{O}$ excerto abaixo nos mostra o quanto a literalidade da linguagem não pertence à cena lúdica. No discurso ficcional do brincar, namoros, bonecos e bonecas desnudos, "prexecas" e "pintos" não estão sob a chancela da proibição, ao contrário, aparecem como personagens e corpos que transitam nesse mundo sem pudores e vergonha. No entanto, diante das vozes e dos olhares adultos, representados também pelas indagações de estranhamento da pesquisadora, as meninas revelam o quanto sabem em que mundo estão com os pés fincados, naquele em que crianças não podem namorar. Mais espantoso ainda é se deparar com o fato de que, neste mundo, lhes é também proibido brincar de namorar.

Ana e Bruna brincam de namoro, manipulando os bonecos, em um canto da sala.

Pesquisadora: Por que eu não posso brincar?

Ana: Porque você é grande.

Pesquisadora: É. Aí menina grande não pode brincar?

Ana: Nem mamá.

Pesquisadora: Mas eles não estavam namorando?

Ana: Não!

Pesquisadora: O que é que eles estavam fazendo?

Ana: Namorando.

Pesquisadora: Ué. E aí? Menina pequena pode brincar de namoro?

Ana: De brincadeira pode, mas de verdade não.

Pesquisadora: Menina pequena pode namorar?

(As meninas acenam negativamente)

Pesquisadora: Não. Mas pode brincar?

Bruna: Só a boneca é que pode.

Pesquisadora: Só a boneca.

Trazendo como um dos eixos de suas reflexões a relação entre crianças e adultos, Sutton-Smith (2001) discute as retóricas sobre o brincar, ressaltando como, muitas das vezes, estas representam discursos que racionalizam e definem a brincadeira da criança como forma de controlá-la e administrá-la. Uma das retóricas mais criticadas pelo autor é a do progresso, caracterizada pela visão de desenvolvimento infantil como processo de adaptação e maturação. A infância, como lugar da inocência e da dependência, representa um mundo distante da vida 
adulta nessa retórica, que atende muito mais às necessidades dos adultos do que às das crianças e, por isso, expressa a hegemonia que os adultos exercem sobre elas. Nessa perspectiva, o desenvolvimento é convocado e consagrado como um aspecto central para compreender a brincadeira da criança.

Olhar para a criança e sua brincadeira para além do escrutínio adulto e acentuar seu caráter subversivo e fantasmagórico a partir das tensões entre crianças e adultos, presentes na vida lúdica infantil, é o que sustenta a crítica de Sutton-Smith à forma como a psicologia do desenvolvimento vem delimitando o brincar. Preocupado muito mais com os modos como as crianças definem suas próprias brincadeiras do que com o olhar adulto sobre estas, o autor salienta o caráter de protesto que o brincar assume diante dos discursos adultos. Com base na abordagem de Scott (1990 apud SUTTON-SMITH, 2001), que considera o folclore infantil como um mundo imaginário povoado por transcrições ocultas (hidden transcripts) ${ }^{9}$, consideradas como protestos contra a retórica adulta sobre as crianças e suas brincadeiras, Sutton-Smith vê no brincar uma arena de tensões entre essas transcrições, que também têm a sua versão pública (public transcripts), definida pelo foco na socialização, na educação e na disciplina das crianças. São essas disputas, afirma o autor, que dão o tom de ambiguidade ao brincar. $\mathrm{O}$ termo "transcrição" (transcript) remete a um modo próprio de a criança traduzir os discursos sociais que circulam em sua vida cotidiana para o espaço da brincadeira. No entanto, as transgressões não estão excluídas dessa tradução, já que também se fazem presentes nas brincadeiras das crianças.

A sexualidade, para Sutton-Smith (2001), é um dos temas que habitam o que ele denomina de fantasmagoria infantil, posto que é uma das transcrições ocultas (hidden transcripts) que atravessam o brincar das crianças e rompem com as fronteiras erigidas e impostas pelas transcrições públicas (public transcripts) tecidas pelos adultos e fortemente comprometidas com a normatização da infância.

Os protestos das crianças contra as transcrições públicas não as retiram por completo das cenas de suas brincadeiras. Para Sutton-Smith (2001), é o confronto entre os valores adultos e a resposta das crianças a esses valores que faz do brincar

\footnotetext{
${ }^{9}$ Os termos "hidden transcripts" e "public transcripts" advêm da obra original em inglês do autor. childhood \& philosophy, rio de janeiro, v. 14, n. 29, jan.-abr. 2018, pp. 241-258 $\quad$ issn 1984-5987 253
} 
gêneros, sexualidades e infâncias: cenas de crianças na contramão da inocência

uma experiência ambígua. Mais do que ambiguidade, é possível ver na brincadeira da criança um espaço dialógico por excelência, ou seja, um terreno fértil para que vozes sociais, produzidas por perspectivas sociais e etárias diferentes, transitem e se transformem no instante em que disputam.

O que temos estabelecido até então é que a sociedade lúdica das crianças, por referir-se aos seus sentimentos sobre a realidade e não à representação direta da realidade como tal, é uma desconstrução dessa sociedade realística. [...] Assim, suas brincadeiras são uma desconstrução do mundo em que vivem. Se o mundo é um texto, a brincadeira é a resposta do leitor a esse texto. (SUTTON-SMITH, 2001, p. 166) ${ }^{10 .}$

Longe de ser um retrato fiel da realidade, a brincadeira não apenas se apresenta como a maneira singular como a criança interpreta o mundo em que vive, mas também como a desconstrução desse mundo. O terreno do brincar é o do discurso em sua potência dialógica, aberto às disputas de sentidos, em que as crianças tecem transcrições sobre os seus mundos de vida.

\section{considerações finais}

À guisa de abertura de problemas, e não de soluções imediatas, pois entendemos que estamos em um fluxo de posicionamentos e ações, situamos a discussão aqui empreendida na esfera das relações entre as múltiplas expressões de gênero e sexualidade e marcadores etários em interface com a psicologia e a educação escolar.

$\mathrm{O}$ que se interroga com estes marcadores, quando os levamos para o contexto escolar são: (1) qual o lugar de crianças e adolescentes no direito à expressão de seus gêneros e sexualidades no contexto escolar? (2) Qual a possibilidade de essas expressões serem reconhecidas e terem existências despatologizadas e viáveis em contextos de aprendizagem, bem como a sua desvinculação de valores moralistas e excludentes; (3) Há protagonismo dessas existências nos conteúdos escolares? (4) Quais as possibilidades das contribuições dos feminismos no questionamento das epistemes ainda presentes nas formas e

10 Citação traduzida pelos autores do original em inglês: What has been established thus far is that children's own play society, because it is about their feelings about reality and not about the direct representation of reality as such, is a deconstruction of that realistic society (...) As such, their play is a deconstruction of the world in which they live. If the world is a text, the play is a reader's response to that text.

254 childhood E philosophy, rio de janeiro, v. 14, n. 29, jan.-abr. 2018, pp. 241-258 issn 1984-5987 
conteúdos escolares? (5) As trajetórias distintas das expressões de gêneros e sexuais de crianças e jovens são reconhecidas pela escola e pelas políticas cognitivas gestadas nela?

Estas interrogações são disparadas diante do modo como a escola se relaciona com a sexualidade. Retomando nossas considerações iniciais sobre o estado atual do banimento dos gêneros e das sexualidades das escolas, um dos eixos de polemização trata das biopolíticas sobre o sexo e os gêneros ainda hegemônicos no processo de escolarização. Diversas pesquisas com crianças pequenas, que se debruçam sobre as questões de gênero e sexualidade na Educação Infantil, trazem à tona, também, estas problematizações e apontam a necessidade de produzir estranhamentos em relação ao que se mantém oculto e restrito, às chancelas dos discursos e às rígidas fronteiras entre os gêneros, dentro dos espaços educativos, como forma de educar para as diferenças, enfrentando preconceitos, discriminações, violências e violações (FARIA, 2006; VIANNA; FINCO, 2009; BUSS-SIMÃO et al, 2010; RIBEIRO, 2011).

A aproximação de crianças à sexualidade ainda é proibitiva, mesmo com as contribuições da psicanálise freudiana que, apesar das críticas binaristas e heteronormativas, inserem a sexualidade como algo que não deve ser negado na vida das crianças. Estes distanciamentos entre crianças e sexualidades estão presentes também nos feminismos, nos quais, em algumas perspectivas mais radicais, as discussões não contemplam a menina ou a mulher adolescente. De maneira geral, em grande parte das ciências humanas e sociais, sexo e gênero se distanciam dos marcadores etários em sua produção, permanecendo a ideia de inocência da criança e a disfuncionalidade da adolescência quando se trata de estes temas.

Preciado (2013) nos alerta sobre a situação da criança quando proibida de expressar seu gênero e seu desejo. Sob o argumento de proteger seus direitos, criam-se dispositivos de proteção (que mais se aproximam de punição) da criança para garantir os roteiros que definem a correspondência sexo-gênero e que a inscreve como supostamente heterossexual. De fato, o que é protegido, segundo 
Preciado, é a normatização de gênero e da sexualidade (na heternorma) das crianças e não seus direitos.

Em algumas de suas linhas, os feminismos são predominantemente adultocêntricos, ou seja, excluem o marcador etário como parte da interseccionalidade necessária para se pensar os gêneros e as sexualidades. A psicologia, lugar de nossa enunciação, do mesmo modo, quando se ocupa da educação, se vincula às considerações psicanalíticas - às trajetórias oral, anal, fálica e de latência -, que afirmam um telos da sexualidade e dos gêneros, advindo do modelo patriarcal e heteronormativo.

$\mathrm{Na}$ perspectiva feminista, a afirmação da politização da esfera pessoal tensiona o público e o privado como experiências sem bordas. O público é o que se torna exposto. O privado é o que está guardado, posto em segredo, colocado à margem. Tradicionalmente moderna, esta relação público e privado remete a localizações que definem os gêneros e as sexualidades como pertencentes ao privado, do segredo, da vida familiar, já que o espaço público é o da razão, da vida coletiva e da inserção na normatividade. Nessa lógica, na educação escolar, os gêneros e as sexualidades são pertencentes à vida cotidiana, e como tal, não cabem ser incorporados aos conteúdos escolares e nem devem circular existencialmente nelas. O discurso corrente busca legitimar esses assuntos como algo da ordem familiar, portanto do privado. A escola, como sendo da ordem da racionalidade e da neutralidade, tendenciosamente os expurga e elimina.

As reflexões e indagações aqui postas buscam escapar do jogo público e privado da modernidade para se inserir nos interstícios, nas porosidades das fronteiras. Assumimos perspectivas sobre gêneros e sexualidades que afirmam a importância de incorporar às epistemes (re)reproduzidas na escola os marcadores etários, considerados como incapazes, faltantes de desejo, de capacidade intelectual, afetiva e social. Crianças e jovens são considerados desviantes que devem ser tutelados para se configurarem segundo o modelo de adulto (branco, heterossexual, cisgênero, racional, justo, produtivo, empreendedor etc).

Em se tratando da produção de conhecimento na perspectiva feminista, Haraway (1995) argumenta em favor da construção de saberes localizados ao 
reiterar o posicionamento marcado por um modo específico de olhar, que longe de se afirmar como um relativismo ou um saber que pode ser ou dizer qualquer coisa a partir de qualquer posição, é um conhecimento que está convocado a prestar contas e, por isso, assume responsabilidades diante das pessoas e dos mundos compartilhados na pesquisa. Tal perspectiva exige, portanto, que seja assumido o saber localizado de crianças e jovens sobre suas sexualidades e gêneros (como suas próprias experiências) em interlocução com os saberes coletivizados, históricos e interseccionais do gênero e das sexualidades. Nesse sentido, considerar o que elas/eles dizem sobre suas sexualidades também implica em considerar o que elas/eles querem saber e também o que não sabem sobre as existências possíveis das expressões dos gêneros, do desejo e da vida erótica. Não se trata de deixar a criança ou o adolescente à deriva, ou somente com suas autorreferências. Numa visada restrita da subjetividade individualizada, isto seria o argumento utilizado por muitos, com base no qual, seria exigida uma condução, um roteiro a ser seguido pelas crianças e jovens sobre suas sexualidades e expressões de gênero. $O$ que se propõe tem em conta a ideia de subjetividade inscrita no coletivo, em que o termo coletivo significa o borramento das fronteiras entre o social e o individual, uma superação dessa dicotomia. Assim, as expressões de crianças e jovens sobre suas sexualidades e gêneros estão conectadas a redes mais amplas e também se constituem, ao mesmo tempo, em singularidades que se (re)inventam.

\section{referências}

BAKHTIN, Mikhail. Estética da criação verbal. São Paulo: Martins Fontes, 1992.

BROUGHTON, John M. (org.). Critical theories of psychological developmental. 2. ed. London e New York: Routledge, 1995.

BURMAN, Erica. Desenvolvimento desejado? Contribuições psicanalíticas para o antidesenvolvimento psicológico. A peste, v. 1, n. 2, São Paulo, jul./dez. 2009, p. 269-294.

BURMAN, Erica. Deconstructing neoliberal childhood: Towards a feminist antipsychological approach. Childhood, vol. 19, n. 4, p. 423-438, 2011.

BURMAN, Erica. Limits of deconstruction, deconstructing limits. Feminism \& Psychology, vol. 25, n. 3, p.408-422, 2015.

BUSS-SIMÃO, Márcia; MEDEIROS, Francisco Emílio de; SILVA, Ana Márcia; FILHO, João Josué da Silva. Corpo e infância: natureza e cultura em confronto. Educação em Revista, vol. 26, n. 3, p. 151-168, 2010.

BUTLER, Judith. Problemas de gênero: feminismo e subversão da identidade. 10. ed. Rio de Janeiro: Civilização Brasileira, 2016. 
gêneros, sexualidades e infâncias: cenas de crianças na contramão da inocência

CARVALHO, Cíntia de Sousa; SILVA, Elisângela Ribeiro da; JOBIM E SOUZA, Solange; SALGADO, Raquel Gonçalves. Direitos sexuais de crianças e adolescentes: avanços e entraves. Psicologia Clínica, vol. 24, p. 69-88, 2012.

CASTRO, L. C. Uma teoria da infância na contemporaneidade. In: CASTRO, L. C. (org.). Infância e adolescência na cultura do consumo. Rio de Janeiro: Nau, 1999. p. 23-49.

FARIA, Ana Lúcia Goulart de. Pequena infância, educação e gênero: subsídios para um estado da arte. Cadernos Pagu, n. 26, p. 279-287, 2006.

FERREIRA, Marcelo Santana. Sobre crianças, sexopolítica e escrita de si. Revista Polis e Psique, vol. 6, n. 1, p. 51-64, 2016.

FOUCAULT, Michel. História da sexualidade I: a vontade de saber. 17. ed. Rio de Janeiro: Edições Graal, 2006.

HARAWAY, Donna. Saberes localizados: a questão da ciência para o feminismo e o privilégio da perspectiva parcial. Cadernos Pagu, n. 5, p. 07-41, 1995.

HARAWAY, Donna J. Manifesto ciborgue: ciência, tecnologia e feminismo-socialista. In: TADEU, Tomaz (org.). Antropologia do ciborgue: as vertigens do pós-humano. 2. ed. Belo Horizonte: Autêntica, 2016. p. 33-118.

HARAWAY, Donna. "Gênero" para um dicionário marxista: a política sexual de uma palavra. Cadernos Pagu, n. 22, p. 201-246, 2004.

PRECIADO, Beatriz. Quem defende a criança queer. Jangada-crítica, literatura, artes, n. 1, Viçosa, 2013, p. 96-99.

RIBEIRO, Cláudia Maria. Crianças, gênero e sexualidade: realidade e fantasia possibilitando problematizações. Estudos Feministas, vol. 19, n. 2, p. 605-614, 2011.

SALGADO, Raquel Gonçalves; CARVALHO, Cíntia de Sousa; RODRIGUES, Maria Auxiliador Campos. Quando as meninas brincam de ser mulher: reflexões sobre mídia, cultura lúdica, gênero e sexualidade. In: PASSOS, Mailsa Carla Pinto; PEREIRA, Rita Marisa Ribes (orgs.). Identidade, diversidade: práticas culturais em pesquisa. Petrópolis, RJ: DP et Alii; Rio de Janeiro: Faperj, 2009. p. 43-54.

SUTTON-SMITH, B. The ambiguity of play. Cambridge e London: Harvard University Press, 2001.

VIANNA, Claudia; FINCO, Daniela. Meninas e meninos na Educação Infantil: uma questão de gênero e poder. Cadernos Pagu, n. 33, p. 265-283, 2009.

recebido em: 26.09 .2017

aceito em: 27.11.2017 